with special age-oriented working conditions and jobs in various professional groups for the most rational employment of aged workers.

Methods We suggest an innovative methodological model for the preparation of jobs for aged workers, including not only modern hygienic requirements, but also criteria for the adequacy of jobs to the needs of aged workers, as well as integral criteria for the assessment of work ability and adaptability of aged workers to the functional, physiological and psycho-physiological work loads. The proposed model «AgeFriendly Workplaces» includes all stages of professional rehabilitation that allows to take into account individual features of the functioning of the organism of aged workers in strict accordance with their age, profession, availability and duration of work, motivation and work ability level.

Results A study of residual work ability among aged workers showed that $57.2 \%$ of workers « $45+»$ and $96.7 \%$ of workers «60+» need to use ergonomic innovations at work to compensate for the age-related decline in their performance. Cluster analysis revealed reliable differences in the mechanisms of formation of residual work ability among workers « $45+»$ and «60+». The correlations between residual work ability among aged workers « $60+»$ and indicators of their professional anamnesis were proved.

Conclusion The development and implementation of the age management system as one of the most fundamental in solving the employment problems of those in pre-retirement and retirement age will allow a more gentle and smooth approach to the issue of extending the working age in Russia.

\section{WORKING ENVIRONMENT AND WORK RETENTION OF AGEING WORKERS}

I Schaumburg*, O Melchior Poulsen*, LL Andersen*. National Research Centre for the Working Environment, Denmark

\subsection{6/oemed-2018-ICOHabstracts.119}

Introduction Demographic changes will profoundly decrease the fraction of the population being at working age in the Nordic countries. This will increase pressure on the Nordic welfare systems, and increased work participation and prolonged work life is therefore high on the political agenda. A recent project showed that the working environment has high impact on early retirement to both disability pension and voluntary pension. However, the project also revealed that knowledge is still lacking on working environment predictors of early retirement particularly in occupations with high risk of early retirement (e.g. blue collar workers with strenuous work).

Methods Data from the Danish 'Work Environment and Health' survey, which is performed every second year among a representative sample of wage earners between 18 and 64 years (50 806 persons in 2012; 50875 persons in 2014; and 65741 persons in 2016), will be analysed for cross-sectional and prospective associations between working environment and intention to retire early. Analyses will be adjusted for various confounders and stratified for socioeconomic position and selected larger job groups.

Results The Nordic project found the following working environment factors to be predictors of early retirement: Occupational accidents, whole-body vibration, physical work demands (strenuous work, heavy lifting, prolonged standing), quantitative work demands (work speed and time pressure), job control, influence at work, leadership support, conflicts at work, bullying/harassment, and job satisfaction. Results from analysis in 'Work Environment and Health' of the differential impact of the different working environment factors on intention to retire early in different occupations will be presented.

Conclusion The working environment factors of major importance for early retirement in occupations with high risk of early retirement are identified, and possible working environment interventions to improve work retention and prolong work-life are discussed.

\section{THE AGEING WORKFORCE, WOMEN AND THE IMPLICATIONS FOR OCCUPATIONAL SAFETY AND HEALTH}

SM Copsey* Elke Schneider. European Agency for Safety and Health at Work (EU-OSHA)

10.1136/oemed-2018-ICOHabstracts. 120

Introduction The workforce in the EU is ageing; therefore, age-related occupational safety and health (OSH) strategies are crucial. However, men and women face different age-related challenges and are differently affected by issues in the workplace throughout working life. In order to inform policy, debate and future research on sustainable work, it is important to identify and understand these differences.

Methods Published and 'grey' literature were reviewed. Case studies on retaining older workers featuring female-dominated work were described and analysed. Input was received from discussion at two European seminars. Issues explored included caring for relatives, the menopause, MSDs and incorporating a gender-sensitive approach into OSH and ageing workforce actions.

Results The key findings were:

- sex- and gender-related differences in working conditions persist throughout the working life; the cumulative physical and emotional impacts of women's work should not be underestimated;

- support is needed for risk assessments that incorporate the complexities of age and gender;

- long periods in low-level jobs, without career promotion, can lead to long-term exposure to hazards;

- equal access to rehabilitation and vocational training must be addressed;

- simple non-stigmatising workplace measures can support women going through the menopause;

- workplace health promotion strategies need different approaches for male and female audiences; flexible work measures need to be relevant to carers of elderly dependants and to both men and women;

- labour inspectorates should have clear diversity strategies;

- older female workers should be viewed as a valuable asset and the double discrimination that older female workers may face should be addressed through awareness raising.

Conclusion It is important to create sustainable working patterns for older workers, with a specific focus on older female workers, through measures that address workloads, work tasks, flexible working hours, the work-life balance, support in the workplace for specific gender-related health issues and workforce development. 